\title{
Peer Assessment in the Design and Construction of a Reinforced Concrete Lintel
}

\author{
William Sher, Senior Lecturer and Deputy Head
}

School of Architecture and Built Environment, Faculty of Engineering and Built Environment, University of Newcastle, AUSTRALIA

Email: willy.sher@newcastle.edu.au

\begin{abstract}
This case study describes a project in which students designed and constructed a reinforced concrete lintel. The main aim was to provide them with a task that would expose them to the challenges and inter-disciplinary conflicts experienced on construction sites and, in so doing, to simulate industry practice. Students worked in multi-disciplinary groups to prepare the design for a lintel, which they then handed to a peer group. This group then constructed the lintel according to this documentation, and assessed the buildability of the design as well as the efficacy and ergonomics of the documentation. The process of implementing this peer assessment exercise was challenging to staff, and was generally well received by students. Members of staff were able to identify factors which promoted and inhibited peer assessment. It was found that peer assessment, when linked with a real-life simulation in a complex coursework exercise, was worth the effort to both staff and students.
\end{abstract}

Keywords: Design; Peer Assessment; Problem Based Learning, Fabrication 


\section{Teaching Context}

\section{Subject Area}

Essentially this case study documents a technical exercise - the design and construction of a reinforced concrete lintel as part of a programme of academic study. However, the technical aspect is only one element, as students have opportunities to acquire and develop a range of transferable skills. The exercise was part of a module entitled Building Technology (Framed Structures). This module continued the theme of building technology from the students' first year of studies and exposed them to the technology of large, complex buildings. In practice, graduates from these disciplines are involved in the design, construction, costing and management of building and civil engineering projects. The overall aim of the project was to provide a task which would expose them to the challenges and inter-disciplinary conflicts experienced on construction sites. As such, the project provided students with "hands-on" experience in the various rôles that they will be expected to fulfil upon graduation. These included structural design, specification writing, temporary works design, planning, construction, quality control and testing. In addition, the project exposed students to "reallife" issues of coordination, communication, working with others and conciliation.

\section{Instructional setting}

The project was taken by second year students studying for degrees in Construction Engineering Management (CEM), Commercial Management and Quantity Surveying (CMQS) and third year Masters students in Civil and Building Engineering (MEng) at Loughborough University, United Kingdom.

\section{Participants}

Approximately 60 students completed the project whilst at University (20 CEM, 30 CMQS and $10 \mathrm{MEng}$ ). They were supervised by two lecturers and a technician.

\section{Study mode}

All students were engaged in full-time studies.

\section{Pedagogical approach}

The task on which this project is based simulates industrial practice as students are required to execute work based on the designs of others. Students designed a lintel and handed their proposals to a group of peers. This group then constructed the lintel and assessed the efficacy of the design as well as that of the design documentation.

The project enabled student learning through peer-group discussion as part of peerassessment. Students also engaged in experiential learning by: working to the construction details prepared by a peer group; and through interaction with peers when they requested clarification of design details. 


\section{Teaching methods}

The project involved:

- the design of a reinforced concrete lintel

- the production of briefing documents to facilitate its construction

- $\quad$ peer assessment of the design (including the briefing documents)

- the design of temporary works necessary for the construction of the lintels

- $\quad$ the construction of the lintels based on the designs

- $\quad$ peer assessment of lintel construction

- $\quad$ structural testing of the lintels

This project has been delivered on several occasions, generally to groups of sixty students. To accommodate this number and to simulate a "real life" experience, all work was done in groups of three or four. Students chose their own group members and then proceeded to design the lintels. The resulting documentation was then handed to other groups who built the lintel according to this design documentation. A flow chart of this sequence of operations is given in Figure 1. This shows how documents were passed between groups so that work could progress and also shows the points at which assessment was completed. 
W. Sher: Peer Assessment in the Design and Construction of a Reinforced Concrete Lintel

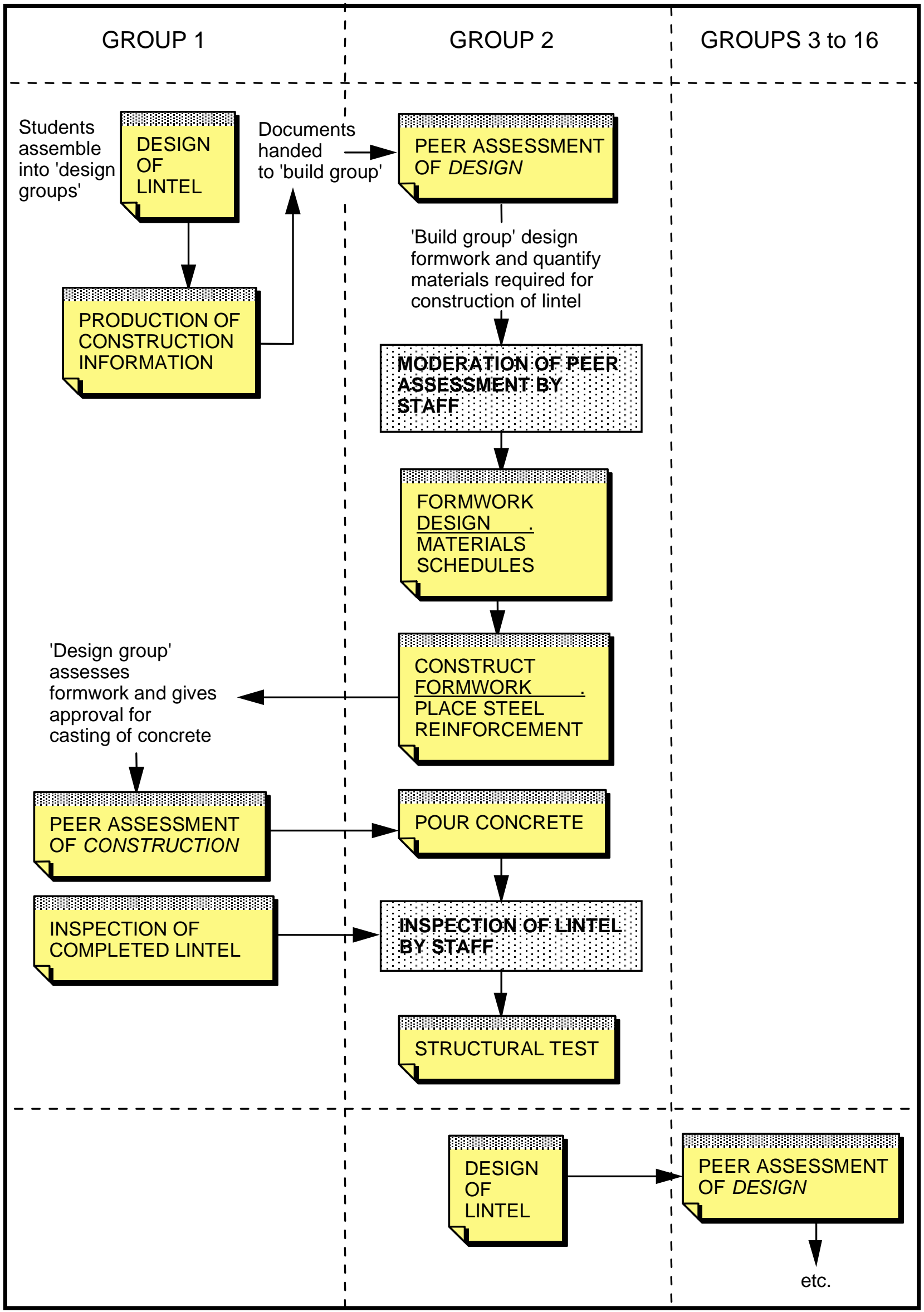

Figure 1: Flowchart of the activities of the lintel project 


\section{How the project was planned}

In devising the project, staff arranged for the following to occur:

- $\quad$ Students would hand in their completed designs to their tutors. These designs needed to take into account the following:

i. how strong the lintel needed to be

ii. it was to be built into the external wall of a brick house

iii. how to maintain the weatherproofing and visual characteristics of the external wall

- $\quad$ Staff would allocate each set of design documentation to another group.

- $\quad$ Groups would then be asked to assess the design efforts of their peers in terms of criteria the class had established by consensus at an earlier stage. Figure 2 provides a sample page of the assessment sheets used.

- $\quad$ All groups would then take on the role of construction contractors and would quantify the materials needed for the construction of their lintel. This would involve them in formwork (or "temporary works") design as they would have to consider how to construct a mould capable of containing and supporting wet concrete.

- $\quad$ Staff would then ask students to prepare a list of the materials they required to build their lintels. These lists would then be handed to our laboratory technicians who would purchase and cut the materials to the sizes required.

- $\quad$ Students would then assemble their formwork, fix reinforcement and call on their designers to approve their work. (This procedure mirrors the practice on construction sites where consultant engineers generally check the quality of formwork and inspect the positioning and quantity of reinforcement before concrete is placed). To formalise this approval, the design teams would complete an assessment sheet (similar to that shown in Figure 2). Plate 1 shows the formwork and reinforcement for a lintel prior to placing of concrete.

- $\quad$ Once this second assessment had been completed, the construct groups would mix and place concrete according to the designer's specifications and leave the lintels suitably protected so that the concrete could set. After an appropriate time, construct groups would remove the formwork from the hardened concrete.

- At this stage design groups would carry out a further visual inspection of the completed lintels.

- $\quad$ After an appropriate curing period the lintels would be placed in a test rig and loads applied to simulate site conditions. Plate 2 shows one of the lintels during testing. 
W. Sher: Peer Assessment in the Design and Construction of a Reinforced Concrete Lintel

- $\quad$ The marks for the project were to be allocated as follows:

DESIGN

Design

$65 \%$

Achievement of design loads

$5 \%$

CONSTRUCT

Construction

$15 \%$

Cutting list

$10 \%$

Quality (determined by 'as-built' inspection)

$5 \%$

- $\quad$ The project contributed half of the coursework component of the module mark.

- $\quad$ All these activities were spread over two terms. A programme indicating this is given in Figure 3 . 
Group No. being assessed

Group No. doing assessment

1 CLARITYIPRESENTATION (20\%)

1.1 The text/calculations was clear and unambiguous

\begin{tabular}{|l|c|l|c|l|}
\hline $\begin{array}{l}\text { POOR } \\
\text { 0 to } 1 \%\end{array}$ & $2-4 \%$ & $\begin{array}{l}\text { AVERAGE } \\
5-6 \%\end{array}$ & $7-8 \%$ & $\begin{array}{l}\text { EXCELLENT } \\
9-10 \%\end{array}$ \\
\hline
\end{tabular}

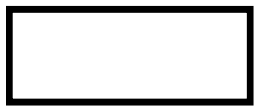

1.2 Sketches were included and were well drawn, clear and consistent with the text

\begin{tabular}{|l|c|c|c|c|}
\hline $\begin{array}{l}\text { POOR } \\
\text { 0 to 1\% }\end{array}$ & $2-4 \%$ & $\begin{array}{c}\text { AVERAGE } \\
5-6 \%\end{array}$ & $7-8 \%$ & $\begin{array}{l}\text { EXCELLENT } \\
\mathbf{9 - 1 0 \%}\end{array}$ \\
\hline
\end{tabular}
$\begin{aligned} & \text { BUILDABILITY (20\%) } \\
& 2.1\end{aligned} \quad$ All aspects of the design of the lintel itself applied good principles of buildability

2.1 All aspects of the design of the lintel itself applied good principles of buildability

\begin{tabular}{|l|c|l|c|l|}
$\begin{array}{l}\text { POOR } \\
\text { 0 to 1\% }\end{array}$ & $2-4 \%$ & $\begin{array}{l}\text { AVERAGE } \\
5-6 \%\end{array}$ & $7-8 \%$ & $\begin{array}{l}\text { EXCELLENT } \\
9-10 \%\end{array}$ \\
\hline
\end{tabular}

2.2 All aspects of the brick/block detailing applied good principles of buildability

\begin{tabular}{|l|c|l|c|l|}
\hline $\begin{array}{l}\text { POOR } \\
0 \text { to } 1 \%\end{array}$ & $2-4 \%$ & $\begin{array}{l}\text { AVERAGE } \\
5-6 \%\end{array}$ & $7-8 \%$ & $\begin{array}{l}\text { EXCELLENT } \\
9-10 \%\end{array}$ \\
\hline
\end{tabular}
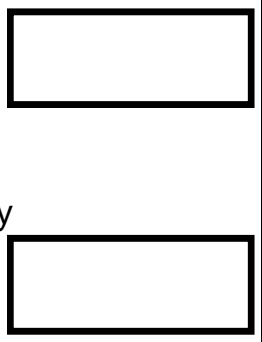

3 BRICK DESIGN/DETAILING (15\%)

3.1 The brick/block aspects met the brief and relevant Building Regs.

\begin{tabular}{|c|c|c|c|c|}
\hline $\begin{array}{l}\text { POOR } \\
0 \text { to } 1 \%\end{array}$ & $2-4 \%$ & $\begin{array}{l}\text { AVERAGE } \\
5-6 \%\end{array}$ & $7-8 \%$ & $\begin{array}{l}\text { EXCELLENT } \\
9-10 \%\end{array}$ \\
\hline
\end{tabular}

3.2 Issues such as cavity drainage, brick support, external brick appearance etc. have been well covered

\begin{tabular}{|l|l|l|l|l|}
\hline POOR & $2-4 \%$ & $\begin{array}{l}\text { AVERAGE } \\
5-6 \%\end{array}$ & $7-8 \%$ & $\begin{array}{l}\text { EXCELLENT } \\
9-10 \%\end{array}$ \\
\hline
\end{tabular}

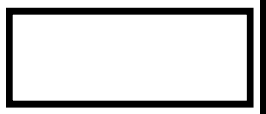

4 CONCRETE MIX DESIGN (15\%)

4.1 Calculations are accurate and assumptions correct

\begin{tabular}{|l|l|l|l|l|}
\hline POOR & $2-4 \%$ & $\begin{array}{l}\text { AVERAGE } \\
5-6 \%\end{array}$ & $7-8 \%$ & $\begin{array}{l}\text { EXCELLENT } \\
9-10 \%\end{array}$ \\
\hline
\end{tabular}

Figure 2: Sample of page 1 of the design assessment sheet 
W. Sher: Peer Assessment in the Design and Construction of a Reinforced Concrete Lintel

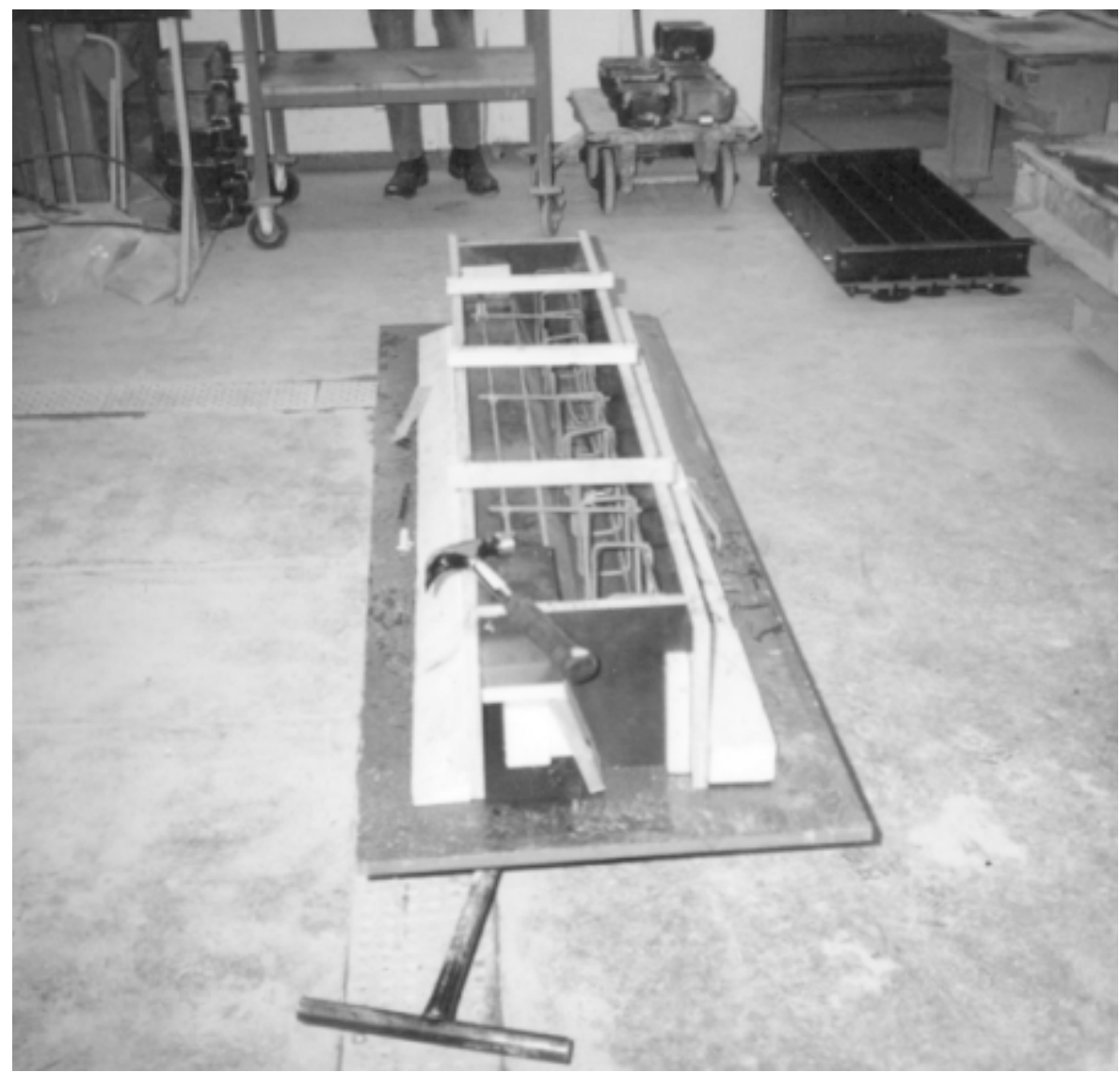

Plate 1: Lintel formwork and reinforcement prior to placing of concrete

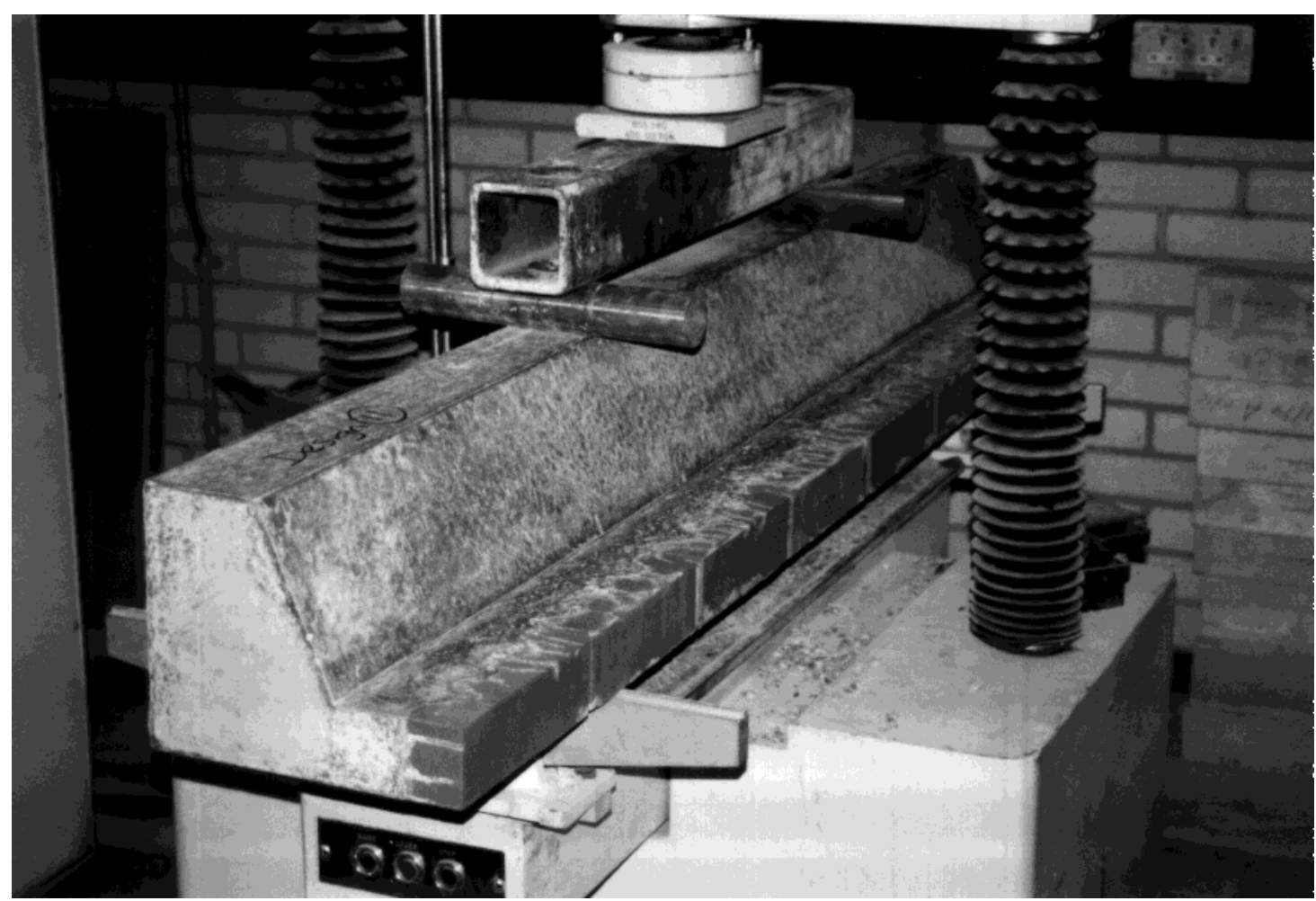

Plate 2: One of the lintels during testing 
W. Sher: Peer Assessment in the Design and Construction of a Reinforced Concrete Lintel

\begin{tabular}{|c|c|c|}
\hline Wk \# & Activity & Deadline \\
\hline 1 & Concept/shape design & \\
\hline 2 & Concept/shape design & \\
\hline 3 & Reinforcement design & Develop assessment criteria \\
\hline 4 & Reinforcement design & \\
\hline 5 & Concrete mix design & \\
\hline 6 & Concrete mix design & $\begin{array}{l}\text { DESIGN WORK COMPLETE BY END } \\
\text { WEEK } 6 \text { SWAP DESIGNS }\end{array}$ \\
\hline 7 & Formwork design & \\
\hline 8 & Formwork design \& Cutting List & Submit Buying List BY END WEEK \\
\hline $9 \& 10$ & STUDY BREAK \& EXAMS & \\
\hline 11 & $\begin{array}{l}\text { Formwork and reinforcement assembly } \\
\text { (in groups) }\end{array}$ & \\
\hline 12 & Cast concrete (in groups) & \\
\hline 13 & $\begin{array}{l}\text { Formwork and reinforcement assembly } \\
\text { (in groups) }\end{array}$ & \\
\hline 14 & Cast concrete (in groups) & \\
\hline 15 & $\begin{array}{l}\text { Formwork and reinforcement assembly } \\
\text { (in groups) }\end{array}$ & \\
\hline 16 & Cast concrete (in groups) & \\
\hline 17 & $\begin{array}{l}\text { Formwork and reinforcement assembly } \\
\text { (in groups) }\end{array}$ & \\
\hline 18 & Cast concrete (in groups) & ALL LINTELS COMPLETE \\
\hline 19 & Test lintels and review & \\
\hline 20 & EXAMS & \\
\hline
\end{tabular}

Figure 3: Programme of the project 


\section{What actually happened}

Not all aspects of the project proceeded according to plan. The main differences from our proposals were:

- $\quad$ Construct groups had difficulty arranging meetings with design groups to approve their formwork and reinforcement. We had intentionally arranged for design documents to be handed from group to group in a "roll-on" manner to avoid problems of victimisation occurring in the peer assessment exercises (For example, Figure 1 shows that group two built group one's design but had their design built by group three, and so on). However, this approach proved complex - especially as three different student cohorts were involved (i.e. CEM, CMQS and MEng). Consequently some construct groups went ahead and cast their lintels without the sanction of their designers - a problem particularly prevalent with multi-disciplinary groups. This had obvious implications for peer assessment and in these instances staff awarded moderated marks (as described below) in place of the missing marks. It is interesting to note that arranging inspections by designers in real-life often also causes problems.

- In the case of those construct groups whose designers had failed to assess their efforts before casting concrete, staff ended up marking the visual aspects of the lintels (in much the same way as a "clerk-of-works" on a construction site would do).

- $\quad$ Staff saw the task of producing a list of the materials required to construct the lintels as a relatively trivial part of the project. Some students obviously viewed this task in the same light and paid scant attention to it! Our technicians suffered the consequences as, in some cases, they had difficulty interpreting students' requirements. The assessment of this aspect was subsequently omitted.

- $\quad$ Some students failed to complete their final visual inspections. Again, this had obvious consequences for peer assessment.

- A mechanical breakdown of our testing apparatus meant that testing of the lintels was not carried out with all students present.

- $\quad$ The marking scheme described above was modified to accommodate the problems described here.

It is hard to determine the extent to which these problems affected the project. We would argue that having things not go according to plan reflects everyday conditions on a construction site and, in this context, the problems experienced could be seen to have added value to the project. 


\section{Evaluation of the project and peer assessment}

Staff and students had different reactions to the project and the peer assessment exercises.

\section{$1 \quad$ Reaction of students}

Open revolt! (...at least initially.) Most second year students came to appreciate the value of the project and the assessment exercises. However there was some general discontent and apprehension. Some of the reasons identified include:

- $\quad$ Unease at marking a colleague's work

Students felt ill-equipped and worried about assessing the work of their colleagues. This was especially true of the MEng students who, being in the third year of their studies, were understandably more concerned about passing or failing than other students. (This is mainly due to the increased weighting of third year marks towards the class of their degree).

- $\quad$ Fears of being victimised

Some students felt that they would be penalised if they marked down other students' efforts. We had anticipated this problem and tried to avoid it (as already described). However, we did experience a case where a design group felt aggrieved at the design mark they had received and subsequently appeared to penalise their construct group's efforts. As these marks were moderated, cases such as these resulted in the peer assessed mark being adjusted accordingly.

- $\quad$ Not wanting the responsibility of assessment

This was especially true of the MEng students, who had not been exposed to peer assessment before.

- $\quad$ Being uncertain of the standard required

The scales ranging from POOR to EXCELLENT which we provided on our assessment sheets, (see Figure 2), presented some students with problems. To guide them in using this scheme, we provided hand-outs which described what we considered to be EXCELLENT, AVERAGE and POOR work (see Figure 4). Notwithstanding this, students still felt ill-equipped to measure the efforts of their peers.

- Sceptical of lecturer's motivation

Although no student actually voiced this fear, we were concerned that they felt we were only using peer assessment as a means of reducing our workload or because we couldn't be bothered to mark their efforts ourselves. 
To receive an EXCELLENT MARK for any of the criteria, your submission should include:

- Summary information that describes what you set out to do, how you did it, what your results were, any problems you encountered along the way and how you overcame them.

- Detailed information to back up the above. This would be logically set out with explanatory notes and sketches where appropriate. Your English would be clear and unambiguous and to the point.

To receive an AVERAGE MARK your submission would include:

- Some summary information

- Detailed information (as described above - but not quite as logically set out or as comprehensive). There may be some waffle or 'flowery' language and/or explanations and sketches that were not relevant.

To receive a POOR MARK you would have included:

- No (or very little) summary information

- Some detailed information but it would be difficult to follow, leave out areas and/or include a lot of waffle. Few sketches would have been provided and readers would be left wondering whether you really knew what you were talking about.

Figure 4: Information provided to assist completion of peer assessment forms Reaction of staff

Staff were generally pleased with the way the project and the assessment exercises progressed. We are fortunate in that most of those involved with the module support innovation but the situation could clearly be different if members of staff were unsupportive and / or unwilling to experiment with novel approaches.

\section{$3 \quad$ Benefits to students}

\section{- $\quad$ Taking responsibility}

The student groups had to take responsibility for considerably more aspects and activities than is normally the case for a typical project in our department. We consider this to be a positive and developmental feature of the exercise.

- Real-life situation

The project provided a "real life" experience of some of the challenges and problems encountered in the construction industry. Although few students 
had worked in the industry they were able to relate to the task in hand and generally enjoyed the work. A point not readily appreciated by some students was that the conflicts they experienced with their peers were similar to those they were likely to encounter in the workplace.

- $\quad$ Student interaction

The nature of the project meant that students had to interact and solve organisational as well as technical problems if they were to succeed. Furthermore, consensus had to be reached in the assessment process, requiring groups to learn to accommodate different views and come to a decision.

- $\quad$ An opportunity to develop skills in evaluating other students' efforts

We saw this as a key aspect of students' development. All those participating are likely to work in management roles and need to be able to judge the efforts of those they work with. This project is a tentative step towards tertiary education developing these skills. In addition, an appreciation of quality and the skill of developing quality consciousness is essential for construction professionals.

- $\quad$ Formative assessment

Few current coursework projects in our department provide an opportunity for formative assessment. We see the fact that this project does provide this chance as a positive aspect of the overall project. Brown and Knight (1994) provide a detailed discussion on the benefits of formative assessment.

\section{$4 \quad$ Benefits to staff}

- $\quad$ Saving staff time

We had hoped that getting students to participate in assessment would reduce the time we spent marking. This was not the case but it was also the first time we had tried peer assessment on this scale. In our experience, peer assessment does not necessarily result in a reduction of staff-time - a factor that some colleagues may find surprising (and perhaps disappointing!). Considerable care and effort needs to be directed to structuring and managing such exercises. If these are not carefully considered, additional time may have to be spent in, for example, repeating instructions to individual groups, altering procedures to cater for factors not considered, and even resorting to traditional assessment practices. Such wasted effort will, in our experience, quickly outweigh potential timesavings of students assessing the work of their peers. There is a learning curve that tutors will experience when adopting these procedures, but engaging in peer assessment with the primary goal of saving substantial time is, in our experience, a false expectation. 
- $\quad$ Potential long-term benefit of less drudgery in marking

Our involvement in peer assessment meant that we spent more time discussing the project and the results with the students and less time sitting on our own marking similar scripts. This interactive approach significantly reduced the drudgery normally associated with tutors assessing large numbers of students.

- $\quad$ Early awareness of ambiguities / problems in briefing documents

As a result of our close contact with students, we became aware of ambiguities in the wording of our brief and in the nature of the problems we had set. This feedback would have been difficult to obtain in a traditional group project environment.

- $\quad$ Opportunity to develop new ideas to enhance coursework

On more than one occasion, the comments and questions of students made us feel "Why didn't I ask that?" or "They didn't really appreciate what I was after - next time I'll phrase the question like this..." There are no doubt other situations where this kind of feedback is available but we felt that this was a valuable by-product of peer assessment.

- $\quad$ Getting to know students better

The close contacts we had with student groups enabled us to get to know them both as individuals and in a group environment. The environment generated by group projects incorporating peer assessment is markedly different from traditional lectures and tutorials and we would contend that it promotes a more open and equal interaction between staff and students.

\section{What will be changed next time?}

Unfortunately financial constraints have prohibited this project from being delivered over the past few years. In the event that we to do resurrect the exercise, staff have identified the following aspects to be addressed:

- $\quad$ Rely less on students choosing the basis for assessment

As already mentioned, we allowed students to choose the criteria for assessing their work. We reviewed these criteria and drew up the assessment sheets referred to earlier. With hindsight, we should also have marked a project as a "dry-run" to test the criteria as, in some cases, we found that groups interpreted aspects differently. We were probably too keen to use the criteria suggested and should have reviewed them more critically.

- Influence the composition of groups.

We allowed students to choose their own group members. This resulted in most groups being drawn from one discipline (i.e. construction management, quantity surveying or civil engineering) as students preferred to work with their 
friends. This situation does not reflect conditions in the construction industry where the design (or construct) team on a project is seldom the same for another project. In subsequent projects we thus assembled groups that reflected the disciplines students are likely to work with in industry. This was also problematic as students experienced difficulties in locating students they did not know. Problems of group composition are not unique and Brown (1996) provides succinct guidelines and suggestions on this.

- $\quad$ Moderate more

We had hoped to spend minimal time on moderation. Our intention was simply to review the assessment sheets, the completed lintels and the results of the stress testing of the lintels and adjust final marks as and where necessary. Again, with hindsight, we should have spent more time moderating and communicating with students.

- $\quad$ Make the assessment sheets simpler

The sheets we drew up (see Figure 2) provided a range of marks for each assessment criterion. We included these so that students could complete all the arithmetic necessary to arrive at a final mark. In practice this proved too complex as the students had enough trouble deciding on one of the five categories provided, let alone refining their choice to a specific mark. In addition, these sheets were filled in at an early stage of the project, prior to moderation. This was not always appropriate as they indicated an absolute mark which could change due to moderation before a final mark was awarded.

- $\quad$ Plan to minimise victimisation

Some students expressed fears about being victimised by their peers during assessment. As already mentioned, this did appear to affect one group. One way of addressing this is to include a section in the marking sheets which requires students to justify the mark they have allocated.

- $\quad$ Provide examples of excellent work

As already mentioned, students found it difficult to decide on the categories provided in our assessment sheets. An approach we tried out in subsequent exercises was to provide an example of excellent work. This meant that, prior to our peer assessment meetings, we went through all submissions and marked a good (but not necessarily the best) project. We then provided this anonymously as an example to those assessing. This proved successful in that students felt more confident of their assessments.

\section{What lessons have been learnt?}

- $\quad$ Start peer assessment as early as possible

Students' attitudes to assessment seem to harden during their academic career. We found that second year students were more receptive to the 
project and to the novel aspects of peer assessment than third years. Other peer assessment exercises with first year students have confirmed to us that peer assessment needs to be incorporated into the assessment culture of an academic institution at an early stage in students' careers if it is to be successful.

- $\quad$ Keep it simple

An overriding principle we learnt is the need to keep things simple. Areas that proved complex were the assessment sheets and the "roll-on" system of passing documentation from one group to another. However, potentially complex exercises may provide pedagogically stimulating opportunities. In the context of the example described here, the interaction between designers and constructors illustrates not only the work students are eventually to find themselves working in, but also the challenges and rewards of this environment. Over-simplification might have lost these attractions. Our recommendation is thus to be aware of the problems of complex projects. Start with modest aspirations and evolve to more complex situations over time.

- $\quad$ Stress the formative aspects of assessment

Students need to be made aware of the objectives of peer assessment. We did not do this effectively initially and had to brief students mid way through the project. Once this was done we found them generally more receptive and co-operative. A factor likely to influence projects such as those described here is the introduction of reflective skills development tools such as RAPID (http://rapid.lboro.ac.uk). By 2005/6 all Higher Education Institutions will be expected to apply Personal Development Planning tools such as RAPID and students will be better able to relate the learning outcomes of various exercises to the competencies expected of those in their chosen profession. RAPID requires students to assess their own skills, and it is likely that experience of self assessment will make students less apprehensive about peer assessment.

- $\quad$ Commit time up front and in the open

Students need to be made aware of the time and effort staff have put into preparing a project. This is, no doubt, true for all projects but it is especially so for those incorporating peer assessment. As already mentioned, students may feel that staff are primarily interested in reducing their own workload and are simply avoiding the task of assessment.

- Brief students well, and in detail

This is an essential ingredient. In a project such as this, students need to be made aware of many issues and this cannot always be adequately explained in a hand-out. 
- $\quad$ Moderate marks

It became apparent that few students felt that their peers were competent to assess their work. This may be due to the fact that those we were involved with had minimal experience of peer assessment. However, it is essential that students see staff as being involved in the assessment process if these fears are to be alleviated. Moderation of marks is an ideal way for this to occur.

\section{Issues still to be addressed}

The peer assessment exercises documented here record the efforts of staff over a period of several years. Although we feel we have accumulated expertise in this approach, we acknowledge that there are still issues to be addressed. Some of these include:

- How to address student concerns

Some of the anxiety caused by peer assessment may be due to students not wanting the responsibility of passing or failing a colleague. An on-line peer assessment tool developed at Loughborough University (http://pass.lboro.ac.uk) allows students to assess the efforts of their peers, but does not present them with the final mark awarded. This system has received a positive response from students. It appears that students are willing to participate in peer assessment, so long as there is some "distance" between them and the mark awarded.

\section{How to keep assessment simple but also comprehensive}

The time allowed for peer assessment was tight and needed to be used effectively. In general, if time constraints are responded to by making assessment superficial, the whole exercise becomes a farce. Clearly assessment needs to be simple and effective. The assessment sheets we used (See Figure 2) proved too complex. Simplifying the grading for each criterion to POOR, AVERAGE or GOOD and omitting reference to the marks attracted by each criterion may make these sheets more effective.

- How to moderate effectively without removing the benefit of peer assessment altogether

There may be conflict between peer assessment and staff moderation. We argue that an element of moderation is essential if staff are to remain in control and Universities' regulations are to be upheld in terms of assessment that contributes to the grades of degrees awarded. During the moderation process it was rarely necessary to alter the marks allocated by students. This demonstrates that, in the majority of cases, peer assessment mirrored staff assessment. Another approach we have used is to use peer assessment to rank the relative order of merit of submissions, but to allow staff to award marks. 
W. Sher: Peer Assessment in the Design and Construction of a Reinforced Concrete Lintel

- How to avoid victimisation

How do we avoid groups being victimised? There are clearly difficulties with anonymity in a project such as this.

- $\quad$ How to deal with mixed classes

How do we deal with students that have no experience of peer assessment especially when they are nearing the end of their undergraduate career?

- How to influence conservative members of staff

How do we promote an accepting approach to assessment by conservative members of staff?

\section{Conclusions}

Notwithstanding outstanding issues, staff are positive about the benefits of peer assessment. We feel that the lintel project was a successful exercise and benefited students (though we acknowledged that some of them have yet to reflect on the exercise and appreciate the beneficial aspects!). Peer assessment, linked with real-life simulation in a complex coursework exercise is worth the effort to both staff and students. Some of the perceived benefits (such as saving tutor's time) were not realised. However, the real benefits to students and staff have been clearly detailed. There is room for improvement, and we will continue to use this approach as one of the various assessment tools we employ.

\section{Bibliography}

Brown, S. and Knight, P. (1994) Assessing Learners in Higher Education. London: Kogan Page,

Brown, S. (1996) The Art of Teaching Small Groups 1, New Academic, 5 (3) pp 3 - 5

Ewers, T. (1997) Peer Assessment in Music. New Academic, 6 (2) pp 5 - 7

Garner, J. B. (1995) Innovations in teaching and assessment methods in courses in construction. In: Proceedings: Int. Symposium (CIB W89) Construction/Building Education and Research beyond 2000. Orlando, Florida: HMSO, pp 23 - 32

Howson, W. P. (2000). Peer assessment: an initial evaluation of a case study in architectural design. In Allen, H. ed. Proceedings of the Civil and Structural Engineering Education in the $21^{\text {st }}$ Century Conference, Southampton University, Vol 2, pp 363 - 374

Loughborough University (2004) Peer Assessment website. http://pass.lboro.ac.uk/ (accessed 08 December 2004).

RAPID progress file. (2004) http://rapid.lboro.ac.uk (accessed 08 December 2004)

Sher, W. and Twigg, D. (1998) Peer Assessment - A Construction "Tool"? In Brown, S. ed Peer Assessment in Practice, SEDA Paper 102. Birmingham: Staff and Educational Development Association 


\section{Acknowledgements}

The author wishes to acknowledge Professor Alistair Gibb who made a significant contribution to this work, as well as Winnie Wade.

\section{About the author}

William Sher, BSc (Hons), MSc, FCIOB, FAIB

William is Senior Lecturer and Deputy Head of the School of Architecture and Built Environment at the University of Newcastle, Australia. Before this he was Senior Lecturer in the Department of Civil and Building Engineering, Loughborough University. He was Project Director of the RAPID project (Promoting Skill Development on Undergraduate Programmes in Civil and Building Engineering: http://rapid2k.lboro.ac.uk and was Deputy Project Director of the TLTP3 funded CALVisual project: http://calvisual.Iboro.ac.uk/ He was nominated as Loughborough University's representative for the ILT's National Teaching Fellowship Scheme in 2000. 